\title{
ANTROPOMETRIA E ERGONOMIA DO MOBILIÁRIO ESCOLAR
}

\author{
MOURA, Roberta Clarice Meneses (1) NEVES,
}

\section{Antonio Alexsandro (2) BARBOSA, Antonio Carlos Leite (3)}

(1) Universidade Federal Rural do Semi-Árido - UFERSA, Estudante do Curso de Arquitetura e Urbanismo

e-mail:clarice meneses@yahoo.com

(2) Universidade Federal Rural do Semi-Árido - UFERSA, Estudante do Curso de Arquitetura e Urbanismo

e-mail:alexneves.2013@hotmail.com

(3) Universidade Federal Rural do Semi-Árido - UFERSA, Arquiteto e Urbanista, Mestre em Cultura e Sociedade, UFMA

e-mail:antonio.leite@ufersa.edu.br

\begin{abstract}
RESUMO
O trabalho trata-se de uma pesquisa na Escola Municipal Professor Severino Bezerra, na cidade de Pau dos Ferros - Rio Grande do Norte. A pesquisa foi feita com base na observação do posicionamento do aluno/professor, bem como da situação em que se encontrava o mobiliário escolar das salas de aula da instituição e como esse influenciava no rendimento dos agentes. Nessas observações foi possível gerar hipóteses sobre o motivo pelo qual havia alto índice de deterioração desse mobiliário, de acordo com as atitudes avaliadas.
\end{abstract}

Palavras-chave: sala de aula; aluno; aprendizagem.

\section{ABSTRACT}

The work is a research at the Municipal School Professor Severino Bezerra, in the city of Pau dos Ferros - Rio Grande do Norte. The research was done based on the observation of the student / teacher position, as well as the situation in which the school furniture of the institution's classrooms was and how it influenced the yield of the agents. In these observations it was possible to generate hypotheses about the reason for the high deterioration rate of this furniture, according to the assessed attitudes.

Keywords: classroom; student; learning.

\section{INTRODUÇÃO}

A arquitetura está ligada ao design e à ergonomia, no momento em que se entende que esta abrange vários campos do saber, como a educação, o conforto, a comunicação visual, entre outros. Tendo em vista que as discussões a respeito da complexidade das tarefas na sala de aula e o comportamento do aluno advém de sua interação com o mobiliário escolar, observa-se neste trabalho como a ergonomia se relaciona com a educação e quais as contribuições que ela pode proporcionar ao ambiente escolar e, consequentemente, como pode melhorar no rendimento do aluno. Segundo Carvalho (2000), o mobiliário escolar é de suma importância no processo educacional, pois é o responsável pelo conforto físico e psicológico do aluno, favorecendo seu aprendizado e deve ser saudável e adequado ao uso 


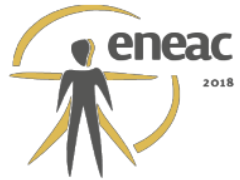

e ao conteúdo pedagógico da escola. Assim, tem como fundamento destacar a importância do uso adequado do mobiliário escolar como resultado para o desenvolvimento e rendimento pessoal do estudante e de forma que este ambiente vem a interferir na sua desenvoltura e aprendizagem. Esse trabalho tem como objetivo mostrar a importância no que se refere aos aspectos ligados à ergonomia na Escola Municipal Professor Severino Bezerra, localizada no município de Pau dos Ferros, Rio Grande do Norte.

\section{CONTEÚDO}

No Brasil, existem poucas publicações relacionadas ao mobiliário escolar. A mais importante delas, elaborada pela Associação Brasileira de Normas Técnicas - ABNT, órgão responsável pela normalização técnica no País, é a NBR 14006/2003 - "Móveis escolares: assentos e mesas para conjunto aluno de instituições educacionais". Esta norma estabelece os requisitos mínimos de mesas e cadeiras para instituições de ensino, nos aspectos ergonômicos, de acabamento, identificação, estabilidade e resistência. No que diz respeito aos aspectos ergonômicos, a norma brasileira foi baseada em estudos antropométricos realizados na Europa, a ISO 5970, por ainda não haver estudos antropométricos da população infanto-juvenil, de abrangência nacional. Como as medidas antropométricas também variam de acordo com a etnia e nacionalidade, não é correto afirmar que as medidas antropométricas da população infanto-juvenil brasileira são semelhantes às de outros países (IIDA, 1997).

Dessa forma, para discutir a relação aluno-mobiliário, é importante levar em consideração a atual realidade das escolas públicas do país, que falham em diversos aspectos estruturais. No tocante a que se tenha uma maior eficiência na transmissão do conhecimento entre o professor e o aluno, é preciso adequar o posto de trabalho e o ambiente aos sujeitos envolvidos neste contexto. Tal adequação permite ao aluno a realização de tarefas na sala de aula, em situação confortável, assim como a transmissão de informações será maior quanto melhor estiver as condições do meio.

\section{CONTEÚDO OBSERVADO}

Para o desenvolvimento desse estudo, foi preciso compreender e esclarecer conceitos, tais como ergonomia, assuntos relacionados à antropometria, equipamentos escolares e o modo e condição que os alunos estudam na instituição. Dessa forma, foi feita uma pesquisa de campo, onde foi analisada a estrutura e as condições em que se encontravam o mobiliário, uma vez que esses são fatores que interferem diretamente no rendimento do aluno. Com base nesses antecedentes, o trabalho foi desenvolvido a partir de leituras sobre o tema proposto e visitas na instituição. A análise do ambiente se deu em três dias de aula e foi possível observar, de fato, a realidade dos estudantes e como se dá a interação com 0 espaço da sala de aula e o mobiliário oferecido. Diante disso, foi possível destacarmos alguns fatores que fazem parte dessa interação e como eles acabam atingindo nessa relação aluno - sala de aula.

\section{RESULTADOS}

Interação do aluno com o meio: É preciso levar em consideração alguns fatores pessoais do aluno, como por exemplo, a falta de concentração. O ambiente desempenha um papel fundamental na formação do aluno e para que a aprendizagem seja efetiva e que haja o desenvolvimento intelectual, ele deve ter contato com um espaço físico estimulante e 


\section{(x) $^{\text {reace }}$}

criativo, o que não foi observado na instituição. É certo que não podemos determinar esse fato a aspectos físicos e estéticos do local, porém de certo modo, é comum a existência desse problema na escola pública. Geralmente os prédios são antigos e dificilmente são feitas reformas para adequar o espaço a esses novos alunos. As gerações mudam e é interessante que esses espaços como a escola e mais precisamente a sala de aula, sejam convidativos e compatíveis com as novas necessidades dos estudantes.

Mobiliário escolar e suas condições ergonômicas: O mobiliário escolar adotado pela escola pesquisa é constituído de dois únicos modelos utilizados em todas as salas de aula da escola, não havendo distinção de dimensões entre as diferentes séries educacionais. De acordo com a ABNT NBR 14006 de 2008, norma que estabelece os requisitos mínimos, exclusivamente para conjunto aluno individual, composto de mesa e cadeira, para instituições de ensino em todos os níveis, nos aspectos ergonômicos, de acabamento, identificação, estabilidade e resistência, é direito do aluno utilizar desse mobiliário adequado, o que infelizmente é uma realidade ainda difícil. Durante a observação do estudo de caso, foi notório que existem várias cadeiras em estado de completa inutilização. $\mathrm{Na}$ instituição, haviam problemas de mobiliário de vários aspectos, cadeiras de madeira descascadas, outras com assentos quebrados, algumas sem as partes de apoio e o mais crítico é que todas estão em total situação de uso pelos alunos, que na maioria são crianças. Foi possível observar também que essa precariedade do mobiliário aparenta ter sido provocado pelo próprio aluno. É certo que o envelhecimento natural do objeto é inevitável, porém há casos de grande intervenção dos estudantes no aceleramento desse desgaste. O que deve ser levado em consideração, é que nem sempre os motivos que os levam a tal prática é apenas de má conduta, todos os outros fatores já citados acabam por influenciar no desempeno desse ato.

\section{CONCLUSÃO:}

O presente trabalho tem preocupação na adequação do ambiente escolar no que diz respeito à importância do uso adequado do mobiliário, uma vez que este ambiente interfere na desenvoltura e aprendizagem do aluno. Assim, observaram-se alguns pontos que podem influenciar no desempenho, tanto educacional, quanto pessoal e mental do aluno e concluiuse o que era óbvio: a falta de seguimento das Normas Regulamentadoras é um dos principais pontos influenciadores. A avaliação comportamental indica claramente que um estudo acurado se faz necessário para o desenvolvimento de projetos de carteiras escolares, a fim de se adequar o design do mobiliário à antropometria dos alunos. $O$ dimensionamento de carteiras escolares deve obedecer às variações antropométricas dos estudantes brasileiros, e para isso, um levantamento antropométrico da população estudantil a nível nacional se faz necessário para que haja, consequentemente, melhor o rendimento do aluno.

\section{REFERÊNCIAS BIBLIOGRÁFICAS}

ABNT. NBR 14006. Móveis escolares; assentos e mesas para instituições educacionais; classes e dimensões. 1997.

ASSOCIAÇÃO BRASILEIRA DE NORMAS TÉCNICAS (ABNT). Móveis escolares - Assentos e mesas para conjunto aluno de instituições educacionais - NBR 14006. Rio de Janeiro: ABNT, maio de 2003. 26p.

FERREIRA, Leda Leal. Algumas reflexões sobre a ergonomia. São Paulo: Setor de Ergonomia da Fundacentro, [s.d.]. 